$\begin{array}{ll}\text { Research Square } & \begin{array}{l}\text { Preprints are preliminary reports that have not undergone peer review. } \\ \text { They should not be considered conclusive, used to inform clinical practice, } \\ \text { or referenced by the media as validated information. }\end{array}\end{array}$

\title{
Survival Among Children Under-Five in India: A Parametric Multilevel Survival Approach
}

Ajit Kumar Jaiswal ( $\sim$ ajitjaiswal20@gmail.com )

International Institute for Population Sciences

Manoj Alagarajan

International Institute for Population Sciences

Wahengbam Bigyananda Meitei

International Institute for Population Sciences

\section{Research Article}

Keywords: Under-five Mortality, Survival analysis, India, Parametric, Intra-class Correlation

Posted Date: February 4th, 2022

DOI: https://doi.org/10.21203/rs.3.rs-1252349/v1

License: @) (7) This work is licensed under a Creative Commons Attribution 4.0 International License. Read Full License 


\section{Abstract}

\section{Background}

Many studies have been conducted on under-five mortality in India and most of them focused on the associations between individual-level factors and underfive mortality risks. On the contrary, only a scarce number of literatures talked about contextual level effect on under-five mortality. Hence, it is very important to have thorough study of under-five mortality at various levels. This can be done by applying multilevel analysis, a method that assesses both fixed and random effects in a single model. The multilevel analysis allows extracting the influence of individual and community characteristics on under-five mortality. Hence, this study would contribute substantially in understanding the under-five mortality from a different perspective.

\section{Method}

The study used data from the Demographic and Health Survey (DHS) acquired in India, i.e., the fourth round of National Family and Health Survey (2015-16). It is a nationally representative repeated cross-sectional data. Multilevel Parametric Survival Model (MPSM) was employed to assess the influence of contextual correlates on the outcome. The assumption behind this study is that 'individuals' (i.e., level-1) are nested within 'districts' (i.e., level-2), and districts are enclosed within 'states' (i.e., level-3). This suggests that people have varying health conditions, residing in dissimilar communities with different characteristics.

\section{Results}

Highest under-five mortality i.e., 3.85\% are happening among those women whose birth interval is less than two years. In case of parity, around $4 \%$ under-five mortality is among women with Third and above order parity. Further, findings from the full model is that ICC values of $1.17 \%$ and $0.65 \%$ are the correlation of the likelihood of having under-five mortality risk among people residing in the state and district communities, respectively. Besides, the risk of dying was increased alarmingly in the first year of life and slowly to aged 3 years and then it remains steady.

\section{Conclusion}

This study has revealed that both aspects viz. individual and contextual effect of the community are necessary to address the importance variations in underfive mortality in India. In order to ensure substantial reduction in under-five mortality, findings of the study support some policy initiatives that involves the need to think beyond individual level effects and considering contextual characteristics.

\section{Background}

The World Health Organization (WHO) defines under-five mortality as the death of a child before the age of five [1]. As an unfinished agenda of MDGs, reducing U5 mortality was included in the Sustainable Development Goals (SDGs) [2]. According to the United Nation Inter-Agency Group for child Mortality Estimation (UNIGME), global under-five mortality rate decreased to 39 deaths per 1000 live births in 2018 from 93 in 1990 and 76 in 2000 . Around $59 \%$ decline was observed in total number of U-5 deaths in 2018 (i.e., 5.3 million) from 12.5 million in 1990 [3].

Despite a significant reduction in global under-five mortality rates, from 90.6 per 1000 live births in 1990 to 42.5 per 1000 live births in 2015 [4] an estimated 5.3 million children under the age of five died each year [5].

The burden of under-five mortality is unevenly distributed, with a strong concentration in middle- and low-income countries [6, 7]. In India, under-five mortality is an important health problem and has been declining steadily. According to National Family Health survey, total 109 death per 1000 live births were taking place within the initial 59 months of life in 1992-93 [8]; around 95 in 1998-99 [9]; and 75 in 2005-06 [10]; and 50 in 2015-16 [11]. As per Sample Registration System 2015 estimates, under-five mortality rate in India varied from 13 to 62 deaths per 1,000 live births across states [12].

Many studies have been conducted on under-five mortality in developing countries like India and most of them focused on the associations between individual-level factors and under-five mortality risks. But, only a scarce number of literatures talked about contextual level effect on under-five mortality [13, $14,15,16,17,18,19]$. A notable increase in the coverage of interventions relevant to child survival, such as births in a health facility, skilled birth attendance, antenatal care visit, coverage of breastfeeding within 1 hour of birth and exclusive breastfeeding for children etc. have a significant contribution in reducing child mortality [21].

A great variations in the availability of maternal and child healthcare services are observed among the communities. These community settings are important aspects and may also be relevant in exacerbating or mitigating inequities of population health outcomes across regions [22, 23]. Incorporating communitylevel factors into under-five mortality analyses allows for the identification of health risks associated with specific social structures and community ecologies, which is a critical policy tool for the development of public health interventions [24, 25]. The contextual phenomenon is the inherent opinion of social epidemiology; examining people form residing in the same locality, it resembles that people are almost the same in terms of their health outcomes. Thus, in any population, it is crucial to understand the individual's health outcome without considering contextual factors, either at design or in analyses. In developed and developing countries, under-five mortality is yet to be studied at multiple levels.

Hence, it is very important to have thorough study of under-five mortality at various levels. This can be done by applying multilevel analysis, a method that assesses both fixed and random effects in a single model. The multilevel analysis allows extracting the influence of individual and community characteristics on outcome. In contrast, the application of individual analyses makes it difficult to understand whether variation at the community level is due to their characteristics in the absence of community-level factors. Hence, this study would contribute substantially in understanding the under-five mortality from a different perspective. 


\section{Method Data Source}

The study used data from the Demographic and Health Survey (DHS) acquired in India, i.e., the National Family and Health Survey (2015-16). It is a nationally representative repeated cross-sectional data. The main objective of NFHS-4 is to obtain reliable, valid and comparable data on levels of health and family welfare across a range of key domains for reproductive populations. The survey provides information on a number of indicators included in the Sustainable Development Goals (SDGs) which India is committed to.

Mortality data for the children under a particular mother can be obtained from the complete birth history file provided in the survey data. In the current analysis, we considered only those women who had given most recent births in the 5-years preceding to the survey. Hence, data of 1,90,898 cases were extracted from the Birth file database (i.e., IABR71FL).

\section{Variable Description}

\section{Outcome Variable}

The outcome variable for this study is the risks of death in childhood, measured as the duration of survival since birth in months. It is defined as the risk of death of the child from birth to 59 months (i.e., under-five mortality). Analysis in this study is restricted to live births in the last five years prior to the survey. The children's survival status and the age at death in months (if the child had died) or the last month they were known to be alive (if the child was still living at the time of the survey) were combined to generate the outcome variables for the survival analysis. Those children who have died before completing 59 months of their lives are considered as 'cases' and they were non-censored, whereas children who were still alive at the time of the survey were treated as rightcensored.

\section{Explanatory Variables}

Individual and community level variables that were considered for viable associations with childhood mortality were based on a set of earlier studies [26, 27 , 28 , 29]. Taking into account of the available information in NFHS-4, a set of various socio-economic, demographic variables along with health services utilization factors are obtained in this study. In addition, to examine the community level impact on under-five mortality, proportion of women assessed Full ANC, Institutional delivery and Postnatal Care was generated at district level, in which the participants were dwelling. A couple of studies have utilized community socioeconomic disadvantage as a community-level determinant [30, 31, 32, 33]. We have included available variables pertaining to various policies and programs already in progress to validate the robustness of the estimates and state causation.

\section{Statistical analysis}

Multistage sampling-based this DHS data encompasses respondents by different geographic areas, and the respondents within the same geographical areas are more prone to be correlated with each other. Descriptive analysis was done by evaluating the prevalence of the dependent variable i.e., under-five mortality across the categories of many independent variables.

Multilevel Parametric Survival Model (MPSM) was employed to assess the influence of contextual correlates on the outcome. There are two reason why we employ MPSM in the study. First, this model is appropriate in analysing censored observations. The second reason for using the model is to account for the hierarchical structure of the NFHS data.

The assumption behind this study is that 'individuals' (i.e., level-1) are nested within 'districts' (i.e., level-2), and districts are enclosed within 'states' (i.e., level3), [34]. This suggests that people have varying health conditions, residing in dissimilar communities with different characteristics. We separately analysed and assessed the association between under-five mortality and Community level characteristics to examine the extent to which the covariates at community level influence under-five mortality in India.

\section{Results}

The Kaplan-Meier failure curve indicated that the probability of under-five mortality increased over time. The risk of dying was increased alarmingly in the first year of life and slowly to aged 3 years and then it remains steady (Figure 1).

\section{<FIGURE 1>}

Table 1 shows the percentage of under-five mortality by Socio-economic characteristics. About $3.24 \%$ under-five mortality are taking place in children residing in rural areas than its counterpart where prevalence is only $1.96 \%$. Highest under-five mortality i.e., $3.85 \%$ are happening among those women whose birth interval is less than two years. In case of parity, around $4 \%$ under-five mortality is among women with Third and above order parity. Children of the illiterate and poorest women have highest death prevalence. For instance, $4.39 \%$ and $4.36 \%$ is the prevalence of under-five mortality among the illiterate and poorest wealth quintile women, which is also the highest. It is observed that households using High polluting fuels are having $3.45 \%$ of U-5 mortality which is more than double of the houses using low polluting fuels. Similarly, from the Kachcha houses, $3.44 \%$ child deaths are taking place; while from Pakka houses, it is $2.45 \%$

\section{<TABLE 1>}


Table 2 presents the results of the extent to which Individual determinants along with community contextual factors influence variation in under-five mortality. Total, four models are employed in this study. The results of the null model which has no explanatory variable (i.e., Model 0 ) showed a significant variation in child mortality at individual and community levels. This also implies that the correlation between mothers living in the state and district communities regarding the likelihood of experiencing under-five mortality is $4.76 \%$ and $1.97 \%$, respectively.

After incorporating only contextual factors into the models-1, risks of death remained significant but slightly plummeted in all regions. Prevalence of ANC, institutional delivery and PNC at district level are integrated and it is found that districts with high proportion of women who are assessing full ANC and institutional delivery are facing about [58\%; $\mathrm{p}<0.001 ; \mathrm{Cl}=0.27-0.65]$ and $[60 \% ; \mathrm{p}<0.001 ; \mathrm{Cl}=0.28-0.56]$ less hazard of under-five mortality, respectively. Moreover, as the district level variables taken into account, it is found that and the particular values of the variance at state and district levels (i.e. ICC=2.91\% and $1.29 \%$ ) from the models explains total variance in under-five mortality can be assigned among people living in the same communities.

Further, Model 3 is applied considering only individual characteristics and it is noticed that children from richest wealth indexed houses has a lesser [ $31 \%$; $\mathrm{p}<0.01 ; \mathrm{Cl}=0.52-0.92]$ chances of dying before attaining the age of 5 years. Households without toilet facilities has higher [14\%; $\mathrm{p}<0.01 ; \mathrm{Cl}=0.98-1.32$ ] likelihood of U-5 mortality. The measures of variation remained significant across communities, ICC associated with chances of U-5 mortality estimated as $1.90 \%$ and $0.86 \%$ across state and district levels, respectively.

Further, full model (i.e. model 4) is conducted, which includes all the selected individual and community level variables. Women who practiced long birth spacing such as birth interval with 2-3 years and More than 3 years are having less hazard ratio with $[36 \% ; \mathrm{p}<0.001 ; \mathrm{Cl}=0.58-0.71]$ and $[28 \% ; \mathrm{p}<0.001 ; \mathrm{Cl}=0.211$ 0.27], respectively of under-five mortality than the women with less than 2 years of birth interval. Children from the Women of third and above parity are around [47\%; $\mathrm{p}<0.001 ; \mathrm{Cl}=1.32-1.63]$ more likely to bear the risk of mortality than the women of up to second parity. As the educational status of the mother increased to secondary and higher level, chances of under-five mortality declined by $12 \%$ and $23 \%$ ( $<<0.001)$, respectively. Findings reveal from the full model (i.e., Model 2) that ICC values of $1.17 \%$ and $0.65 \%$ are the correlation of the likelihood of having under-five mortality risk among people residing in the state and district communities, respectively.

\section{$<$ TABLE 2>}

\section{Discussion}

The focus of this paper was to examine the individual and community level factors' effect on under-five mortality and determine the extent to which regional variation affect Under-five mortality in India. There are many studies that have concluded that the risk of death during childhood are because of combined effects of contextual and individual variables, and the effects of exogenous factors at those levels [31, 35, 36]. Whitworth \& Stephenson (2002) also found that village- or community-level factors were more important in accounting for child mortality than mother- or individual-level characteristics [37].

Our descriptive findings reveal that U-5 mortality is quite higher in rural areas than urban areas. There might be a couple of reasons behind the phenomena. First, three fourth of the respondents were from rural areas, whereas only one-fourth from urban areas. This huge differential between rural-urban population structures across regions seems to contribute to regional deaths differential in India. Second, it is obvious that the differentials in the distribution of health care facilities exist between rural and urban communities [38, 39].

Our findings go in line with the earlier studies where authors have tried to look into under-five mortality and its predictors. For instance, studies examined that factors such as low level of education, unimproved drinking water, and low family income, short birth interval, and birth delivery place continue to put children at risk $[13,14,15,16]$. Besides, there are some demographic determinants associated with under five mortality such as maternal age at birth, birth spacing pattern, parity, and size of the children at birth $[17,18]$. Studies show that infant and child mortality is high among the first born, but relatively low among second and the third order births [19]. The length of the birth interval has a negative association with the infant and child mortality, i.e., the smaller the birth interval, the higher is the child mortality [20]. Lack of proper sanitation is a major public health risk that affects child health much more than other members of the communities. Child mortality is majorly affected by household hygiene. Many of the households still do not have access to modern toilet facilities particularly communities living in the hills [40].

In our study, apart from individual characteristics, the community level characteristics, i.e. full ANC and delivery in health care facility, exert significant effect on under-five mortality includes full ANC and delivery in health care facility. This finding may be attributed to inequality in the distribution and use of health facilities [38, 39, 41, 42].

After adjusting for the selected district-level and individual-level variables, finding suggested higher under-five mortality clustering are at the community level rather than individual level. For this, there may be a reasonable understanding that children's interaction with community environment is more likely to be compared with the period under age one [35].

\section{Conclusion}

This study has revealed that both aspects viz. individual and contextual effect of the community are necessary to address the importance variations in underfive mortality in India. In order to ensure substantial reduction in under-five mortality, findings of the study support some policy initiatives that involves the need to think beyond individual level effects and considering contextual characteristics. Policies that address regional disparities in under-five mortality in India must include strategies to improve child health outcomes, particularly during the first year of life.

\section{Limitations}


Besides, there are some caveats which is necessary to be addressed. First, the cross-sectional nature of the Data does not allow making cause and effecting relationship. Second, this study uses State and District-level as proxy for community, so this attribute of the data may lead to some information biasness because of misclassification of the respondents from different clusters [43]. Lastly, there might be problem of auto-correlation because some variables have been generated at Community level with individual-level variables.

\section{Declarations}

Ethics approval and consent to participate: This research does not have an ethical code because the data source used in this study gathered from publically available data and these data considered as secondary data. All methods were carried out in accordance with relevant guidelines and regulations.

Consent for publication: Not applicable.

Availability of data and materials: The datasets used in the current study are freely available from the Demographic Health Survey. https://dhsprogram.com/Data/

Competing interests: None.

Funding: This research received no specific grant from any funding agency, commercial entity or Non-Profit organization.

Authors' contributions: A.K.J. lead the investigation and formal analysis, and wrote the original draft. W.B. Meitei, lead the conceptualization, investigation, edited the first draft of this study. M.A. supported the conceptualization and investigation of this study, and reviewed the first and final draft. All authors reviewed the manuscript. The author(s) read and approved the final manuscript.

Acknowledgements: We appreciate access to fourth Indian NFHS dataset and used for the analyses in this manuscript. In addition, the authors are thankful to Mr. Mrinmoy Pratim Bharadwaz for his feedbacks and methodological support that enrich this paper technically.

\section{References}

1. Ahmad OB, Lopez AD, Inoue M. The decline in child mortality: a reappraisal. Bull World Health Organ. 2000;78(10):1175-91.

2. Kumar S, Kumar N, Vivekadhish S. Millennium development goals (MDGs) to sustainable development goals (SDGs): Addressing unfinished agenda and strengthening sustainable development and partnership. Indian J Community Med [Internet]. 2016;41(1):1-4. Available from:

http://dx.doi.org/10.4103/0970-0218.170955

3. UNICEF. (2015). Levels and trends in child mortality: report 2019. Estimates developed by the UN Inter-agency Group for child mortality estimation.

4. Khodaee GH, Khademi G, Saeidi M. Under-five Mortality in the World (1900-2015). International Journal of Pediatrics. 1900;3:1093-5.

5. Liu L, Oza S, Hogan D, Chu Y, Perin J, Zhu J, et al. Global, regional, and national causes of under-5 mortality in 2000-15: an updated systematic analysis with implications for the Sustainable Development Goals. Lancet [Internet]. 2016;388(10063):3027-35. Available from: http://dx.doi.org/10.1016/s01406736(16)31593-8

6. Kazembe L, Clarke A, Kandala N-B. Childhood mortality in sub-Saharan Africa: cross-sectional insight into small-scale geographical inequalities from Census data. BMJ Open [Internet]. 2012;2(5):e001421. Available from: http://dx.doi.org/10.1136/bmjopen-2012-001421

7. Wang H, Liddell CA, Coates MM, Mooney MD, Levitz CE, Schumacher AE, Apfel H, lannarone M, Phillips B, Lofgren KT, Sandar L. Global, regional, and national levels of neonatal, infant, and under-5 mortality during 1990-2013: a systematic analysis for the Global Burden of Disease Study 2013. The Lancet. 2014 Sep 13;384(9947):957-79.

8. IIPS M, Macro OR. National family health survey (NFHS-1), 1992-93: India. Mumbai: International Institute for Population Sciences. 1995.

9. Roy TK, Arnold F, Kulkarni S, Gupta K, Mishra V, Nangia P. National Family Health Survey (NFHS-2), 1998-99. Mumbai: International Institute for Population Sciences. 2000:443.

10. International Institute for Population Sciences. National family health survey (NFHS-3), 2005-06: India. International Institute for Population Sciences; 2007.

11. IIPS I. India National Family Health Survey NFHS-4 2015-16. Mumbai: IIPS and ICF. 2017.

12. Office of the Registrar General \& Census Commissioner, India. Ministry of Home Affairs Government of India: Sample Registration System Statistical Report 2015. New Delhi, 2016. Available from: https://censusindia.gov.in/vital_statistics/SRS_Report_2015/8.Chap\%204-Mortality\%20Indicators2015.pdf.

13. Karim S, Paul K, Chaudhary M, Mukherjee S. Association of Morbidity Among Children with Housing, Water and Sanitation in Urban India: A Policy Perspective. InRegional Development Planning and Practice 2022 (pp. 279-295). Springer, Singapore.

14. Kabir R, Farag M, Lim HJ, Geda N, Feng C. Socio-demographic and environmental risk factors associated with multiple under-five child loss among mothers in Bangladesh. BMC pediatrics. 2021 Dec;21(1):1-9.

15. Jayathilaka R, Adikari H, Liyanage R, Udalagama R, Wanigarathna N. Cherish your children: socio-economic and demographic characteristics associated with child mortality. BMC public health. 2021 Dec;21(1):1-4.

16. Devi M, Karol S. SOCIO-ECONOMIC DETERMINANTS OF HEALTH OUTCOMES IN INDIA.

17. Srivastava S, Upadhyay SK, Chauhan S, Alagarajan M. Preceding child survival status and its effect on infant and child mortality in India: An evidence from National Family Health Survey 2015-16. BMC public health. 2021 Dec;21(1):1-2.

Page 5/11 
18. Ram SS, Ram B, Yadav A. The Effects of Maternal Age on Neonatal and Post-neonatal Mortality in India: Roles of Socioeconomic and Biodemographic Factors. Canadian Studies in Population. 2021 Mar;48(1):59-89.

19. Chandrasekhar S. Infant Mortality, Population Growth and Family Planning in India: An Essay on Population Problems and International Tensions. Routledge; 2012 Aug 21.

20. Ronsmans C. Birth spacing and child survival in rural Senegal. International journal of epidemiology. 1996 Oct 1;25(5):989-97.

21. Rubayet S, Shahidullah M, Hossain A, Corbett E, Moran AC, Mannan I, Matin Z, Wall SN, Pfitzer A, Mannan I, Syed U. Newborn survival in Bangladesh: a decade of change and future implications. Health Policy and Planning. 2012 Jul 1;27(suppl_3):iii40-56.

22. Siddiqi A, Irwin LG, Hertzman C. The total environment assessment model of early child development. Vancouver: Organización Mundial de la Salud. 2007.

23. Ferede T. Multilevel modelling of modern contraceptive use among rural and urban population of Ethiopia. Am J Math Stat. 2013;3(1):1-6.

24. Pickett KE, Pearl M. Multilevel analyses of neighbourhood socioeconomic context and health outcomes: a critical review. Journal of Epidemiology \& Community Health. 2001 Feb 1;55(2):111-22.

25. Stephenson R, Baschieri A, Clements S, Hennink M, Madise N. Contextual influences on the use of health facilities for childbirth in Africa. American journal of public health. 2006 Jan;96(1):84-93.

26. Sear R, Steele F, McGregor IA, Mace R. The effects of kin on child mortality in rural Gambia. Demography. 2002 Feb;39(1):43-63.

27. Antai D. Regional inequalities in under-5 mortality in Nigeria: a population-based analysis of individual-and community-level determinants. Population health metrics. 2011 Dec;9(1):1-0.

28. Singh A, Pallikadavath S, Ram F, Alagarajan M. Do antenatal care interventions improve neonatal survival in India?. Health policy and planning. 2014 Oct 1;29(7):842-8.

29. Getachew Y, Bekele S. Survival analysis of under-five mortality of children and its associated risk factors in Ethiopia. J Biosens Bioelectron. $2016 ; 7(213): 2$.

30. Wight RG, Cummings JR, Miller-Martinez D, Karlamangla AS, Seeman TE, Aneshensel CS. A multilevel analysis of urban neighborhood socioeconomic disadvantage and health in late life. Social Science \& Medicine. 2008 Feb 1;66(4):862-72.

31. Uthman OA. A multilevel analysis of individual and community effect on chronic childhood malnutrition in rural Nigeria. Journal of tropical pediatrics. 2009 Apr 1;55(2):109-15.

32. Major JM, Doubeni CA, Freedman ND, Park Y, Lian M, Hollenbeck AR, Schatzkin A, Graubard BI, Sinha R. Neighborhood socioeconomic deprivation and mortality: NIH-AARP diet and health study. PloS one. 2010 Nov 23;5(11):e15538.

33. Turney K, Harknett K. Neighborhood disadvantage, residential stability, and perceptions of instrumental support among new mothers. Journal of Family Issues. $2010 \mathrm{Apr} ; 31(4): 499-524$.

34. Harttgen K, Misselhorn M. A multilevel approach to explain child mortality and undernutrition in South Asia and Sub-Saharan Africa. IAI Discussion Papers; 2006.

35. Boco AG. Individual and Community Level Effects on Child Mortality: An Analysis of 28 Demographic and Health Surveys in Sub-Saharan Africa DHS Working Papers. Calverton, Maryland, USA. 2010.

36. Antai D. Inequalities in under-5 mortality in Nigeria: do ethnicity and socioeconomic position matter?. Journal of Epidemiology. 2011 Jan 5;21(1):13-20.

37. Whitworth A, Stephenson R. Birth spacing, sibling rivalry and child mortality in India. Social science \& medicine. 2002 Dec 1;55(12):2107-19.

38. Stock R. Distance and the utilization of health facilities in rural Nigeria. Social science \& medicine. 1983 Jan 1;17(9):563-70.

39. Adetunji JA. Infant mortality and mother's education in Ondo State, Nigeria. Social Science \& Medicine. 1995 Jan 1;40(2):253-63.

40. Ladusingh L, Singh CH. Place, community education, gender and child mortality in North-east India. Population, Space and Place. 2006 Jan;12(1):65-76.

41. Pradhan M, Sahn DE, Younger SD. Decomposing world health inequality. Journal of health economics. 2003 Mar 1;22(2):271-93.

42. Say L, Raine R. A systematic review of inequalities in the use of maternal health care in developing countries: examining the scale of the problem and the importance of context. Bulletin of the World Health Organization. 2007;85:812-9.

\section{Tables}


Table-1 Prevalence of Under-five mortality rate by some Socio-economic characteristics with $95 \% \mathrm{Cl}$ in India, 2015-16

Covariates

Child Mortality rate

Place of Residence

Urban

$2.39(2.11,2.67))$

Rural

$3.93(3.80,4.07)$

Birth Interval

Less than 2 years

$4.52(4.18,4.85)$

2-3 years

$3.42(3.09,3.76))$

More than 3 years

$3.18(2.94,3.41))$

Parity

First-Second

$2.68(2.51,2.84))$

Third and above

$5.00(4.65,5.36)$

\section{Educational level}

No education

$5.39(5.00,5.79)$

Primary

$4.05(3.64,4.46)$

Secondary

$2.65(2.40,2.90)$

Higher

$1.48(1.29,1.68)$

Wealth Index

Poorest

$5.39(5.07,5.71)$

Poorer

$4.26(3.87,4.66)$

Middle

$3.36(3.03,3.70)$

Richer

$2.25(1.89,2.62)$

Richest

$1.43(1.23,1.67)$

\section{Quality of water}

Improved

$3.49(3.31,3.67)$

Unimproved

$3.23(2.83,3.63)$

Others

$2.96(0.63,5.29)$

Stool disposal of the child

Safe

$0.83(0.75,0.90)$

Unsafe

$1.20(1.13,1.28)$

Toilet Facility

Improved*Not shared

$2.35(2.13,2.57)$

Shared

$3.13(2.47,3.78)$

Unimproved

$3.17(2.09,4.24)$

No facility

$4.68(4.42,4.94)$

Others

$3.04(-0.07,6.85)$

Cooking Fule

Clean

$2.32(2.09,2.54)$

Solid

$4.18(4.01,4.35)$

Type of house

Kachcha

Semi Pakka

$2.66(2.09,3.22)$

$3.55(3.39,3.71)$

Pakka

$3.42(2.97,3.87)$

Total 
Page 8/11 
Table-2 Multilevel Parametric Survival Model for Under-Five Child Mortality

\begin{tabular}{|c|c|c|c|c|c|c|c|c|c|c|c|c|c|c|}
\hline \multicolumn{5}{|c|}{ Model 0} & \multicolumn{4}{|l|}{ Model 1} & \multicolumn{4}{|c|}{ Model 2} & \multicolumn{2}{|c|}{ Model 3} \\
\hline & HR & $\begin{array}{l}\mathrm{P}- \\
\text { value }\end{array}$ & $\mathrm{Cl}$ & & HR & $\begin{array}{l}\mathrm{P} \text { - } \\
\text { value }\end{array}$ & $\mathrm{Cl}$ & & HR & $\begin{array}{l}\mathrm{P} \text { - } \\
\text { value }\end{array}$ & $\mathrm{Cl}$ & & HR & $\begin{array}{l}P \text { - } \\
\text { value }\end{array}$ \\
\hline Constant & 0.0009 & 0.000 & 0.0008 & 0.0010 & 0.0022 & 0.000 & 0.0017 & 0.0028 & 0.0007 & 0.000 & 0.0005 & 0.0010 & 0.0010 & 0.000 \\
\hline \multicolumn{15}{|c|}{ District level Variables } \\
\hline $\begin{array}{l}\text { Prevalance of } \\
\text { Full Ante-natal } \\
\text { Care }\end{array}$ & & & & & 0.42 & 0.000 & 0.27 & 0.65 & & & & & 0.38 & 0.004 \\
\hline $\begin{array}{l}\text { Prevalance of } \\
\text { Place Of } \\
\text { Delivery }\end{array}$ & & & & & 0.40 & 0.000 & 0.28 & 0.56 & & & & & 0.65 & 0.099 \\
\hline $\begin{array}{l}\text { Prevalance of } \\
\text { Full Post-natal } \\
\text { Care }\end{array}$ & & & & & 1.20 & 0.322 & 0.84 & 1.70 & & & & & 1.51 & 0.110 \\
\hline
\end{tabular}

Individual level Variables

Place of

Residence

Urban ${ }^{\circledR}$

Rural

$\begin{array}{llllll}0.94 & 0.376 & 0.82 & 1.08 & 0.92 & 0.252\end{array}$

Birth Interval

Less than 2

years ${ }^{\circledR}$

2-3 yrs

More than 3

years

$\begin{array}{llllll}0.64 & 0.000 & 0.58 & 0.71 & 0.64 & 0.000 \\ 0.24 & 0.000 & 0.21 & 0.27 & 0.24 & 0.000\end{array}$

\section{Parity}

First-

Second $\circledast$

Third and

$\begin{array}{llllll}1.48 & 0.000 & 1.33 & 1.64 & 1.47 & 0.000\end{array}$

above

Educational

level

No

education ${ }^{\circledR}$

Primary

Secondary

Higher

Wealth Index

Poorest $\AA$

Poorer

Middle

$\begin{array}{llllll}0.92 & 0.340 & 0.78 & 1.09 & 0.96 & 0.593\end{array}$

Richer

Richest

\begin{tabular}{llllll}
1.04 & 0.554 & 0.91 & 1.19 & 1.04 & 0.540 \\
\hline 0.87 & 0.031 & 0.77 & 0.99 & 0.88 & 0.039 \\
0.77 & 0.066 & 0.58 & 1.02 & 0.77 & 0.069
\end{tabular}

Source of

water

Improved $\circledast$

Uimproved

Others

$\begin{array}{llllll}0.92 & 0.326 & 0.79 & 1.08 & 0.91 & 0.244 \\ 1.06 & 0.926 & 0.34 & 3.28 & 1.07 & 0.905\end{array}$

Stool disposal

of the child

Safe ${ }^{\circledR}$ 


\section{Toilet Facility}

Improved*Not

shared ${ }^{\circledR}$

\begin{tabular}{llrrrrrr} 
Shared & 1.05 & 0.601 & 0.87 & 1.26 & 1.06 & 0.566 \\
Unimproved & 1.14 & 0.446 & 0.81 & 1.61 & 1.16 & 0.393 \\
\hline No facility & 1.14 & 0.085 & 0.98 & 1.32 & 1.17 & 0.040 \\
\hline Others & 0.37 & 0.319 & 0.05 & 2.63 & 0.38 & 0.328 \\
\hline
\end{tabular}

Cooking Fule

Clean ${ }^{\circledR}$

Solid

1.10

0.238

0.94

1.29

1.09

0.287

Type of house

Kachcha ${ }^{\circledR}$

\begin{tabular}{|c|c|c|c|c|c|c|c|c|c|c|c|c|}
\hline Semi pakka & & & & & & & 0.97 & 0.737 & 0.81 & 1.16 & 0.96 & 0.648 \\
\hline Pakka & & & & & & & 1.27 & 0.088 & 0.96 & 1.67 & 1.26 & 0.099 \\
\hline $\begin{array}{l}\text { Variance } \\
\text { (cons) } \\
\text { [State] }\end{array}$ & 0.16 & 0.09 & 0.30 & 0.10 & 0.05 & 0.19 & 0.06 & & 0.03 & 0.14 & 0.04 & \\
\hline ICC (\%) & 4.76 & & & 2.91 & & & 1.90 & & & & 1.17 & \\
\hline $\begin{array}{l}\text { variance } \\
\text { (cons) } \\
\text { [State>District] }\end{array}$ & 0.07 & 0.05 & 0.09 & 0.04 & 0.03 & 0.07 & 0.03 & & 0.01 & 0.10 & 0.02 & \\
\hline $\operatorname{ICC}(\%)$ & 1.97 & & & 1.29 & & & 0.86 & & & & 0.65 & \\
\hline
\end{tabular}

\section{Figures}




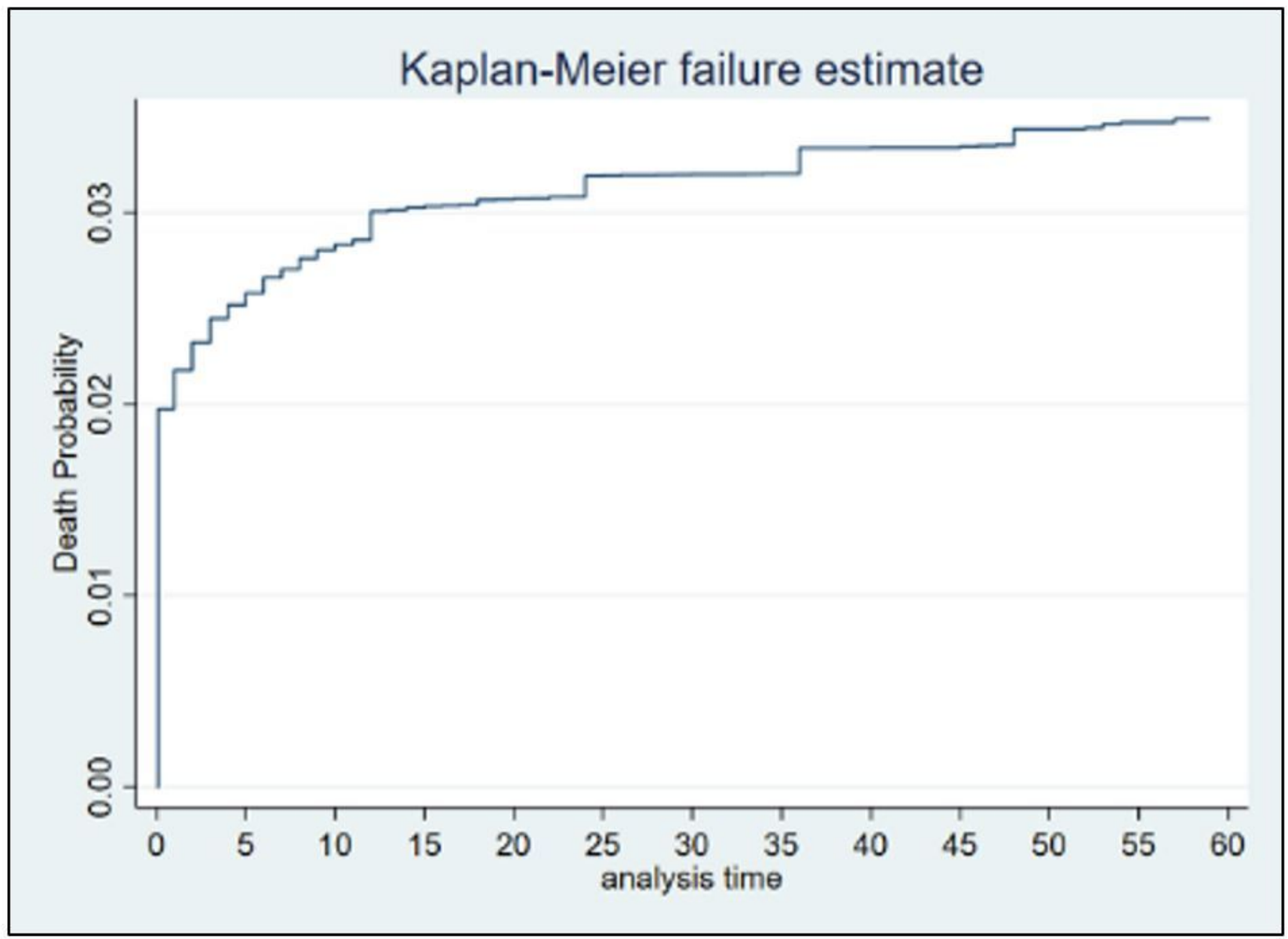

Figure 1

The overall Kaplan-Meier curve of the survival status of under five mortality in India. 